\title{
Erratum to: Simulation factors of steel continuous casting
}

\author{
A. Ramírez-López ${ }^{1,2,3)}$, R. Aguilar-López ${ }^{1)}$, J. González-Trejo ${ }^{1)}$, and M. Palomar-Pardavé ${ }^{1)}$ \\ 1) Department of Materiales, Metropolitan Autonomous University, Mexico City C.P. 02200, México \\ 2) Institute Polytechnic National, Mexico City C.P. 07300, México \\ 3) Institute Technologic Autonomous of Mexico, Mexico City C.P. 01080, México
}

Erratum to: International Journal of Minerals, Metallurgy and Materials

Volume 17, Number 3, June 2010, Page 267

DOI: 10.1007/s12613-010-0304-x

A. Kunold-Bello was added to the author list in error and needs to be removed.

The online version of the original article can be found at http://dx.doi.org/10.1007/s12613-010-0304-x 